\title{
COGENT (COlorectal cancer GENeTics): an international consortium to study the role of polymorphic variation on
} the risk of colorectal cancer

\begin{abstract}
IPM Tomlinson', M Dunlop², H Campbell ${ }^{3}$, B Zanke ${ }^{4,5,6}$, S Gallinger ${ }^{6,7}$, T Hudson ${ }^{4}$, T Koessler ${ }^{8}$, PD Pharoah ${ }^{8}$,

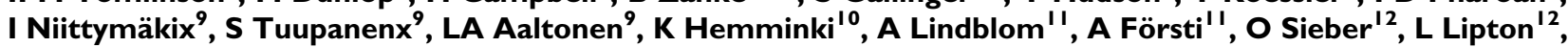
T van Wezel ${ }^{13}$, H Morreau ${ }^{13}$, JT Wijnen ${ }^{14}$, P Devilee ${ }^{14}$, K Matsuda ${ }^{15}$, Y Nakamura ${ }^{15}$, S Castellví-Bel ${ }^{16}$, C Ruiz-Ponte ${ }^{17}$, A Castells ${ }^{16}$, A Carracedo ${ }^{17}$, JWC Ho ${ }^{18}$, P Sham $^{18}$, RMW Hofstra ${ }^{19}$, P Vodicka ${ }^{20}$, H Brenner ${ }^{21}$, J Hampe ${ }^{22}$, C Schafmayer ${ }^{23,24}$, J Tepel ${ }^{24}$, S Schreiber ${ }^{22}$, H Völzke ${ }^{25}$, MM Lerch ${ }^{26}$, CA Schmidt ${ }^{27}$, S Buch ${ }^{22}$, V Moreno ${ }^{28}$, CM Villanueva ${ }^{29}$, P Peterlongo ${ }^{30}$, P Radice ${ }^{30}$, MM Echeverry ${ }^{31}$, A Velez ${ }^{32}$, L Carvajal-Carmona ${ }^{1,31}$, R Scott ${ }^{33}$, S Penegar ${ }^{34}$, P Broderick ${ }^{34}$, A Tenesa ${ }^{2}$ and RS Houlston ${ }^{*, 34}$
\end{abstract}

'Molecular and Population Genetics, Nuffield Department of Medicine, University of Oxford, Wellcome Trust Centre for Human Genetics,

Roosevelt Drive, Oxford OX3 7BN, UK; ${ }^{2}$ Institute of Genetics and Molecular Medicine, University of Edinburgh, MRC-HGU, Western General Hospital, Crewe Road South, Edinburgh EH4 2XU, UK; ${ }^{3}$ Public Health Sciences, University of Edinburgh, Edinburgh EH89AG, UK; ${ }^{4}$ The Ontario Institute for Cancer Research, The MaRS Center, 101 College St, Suite 800, Toronto, Ontario, Canada M5G IL7; ${ }^{5}$ The University of Ottawa Faculty of Medicine, I0I Smythe Rd, Ottawa, Ontario, Canada KIH 8L6; ${ }^{6}$ Cancer Care Ontario, 620 University Ave., Toronto, Ontario, Canada M5G 2L7; ${ }^{7}$ Samuel Lunenfeld Research Institute, Mount Sinai Hospital and University of Toronto, 600 University Ave., Toronto, Ontario, Canada M5G IX5; ${ }^{8}$ Department of Oncology, University of Cambridge, Cambridge, UK; ${ }^{9}$ Department of Medical Genetics, Genome-Scale Biology Research Program, Biomedicum 9, University of Helsinki, Helsinki, Finland; ${ }^{10}$ German Cancer Research Center, Heidelberg, Germany; " Department of Molecular Medicine and Surgery, Karolinska Institutet, CMM02, Stockholm S17176, Sweden; '2 LCCI Biomarker Laboratory, Ludwig Institute for Cancer Research, PO Box 2008, Royal Melboume Hospital, VIC 3050, Australia; ${ }^{13}$ Department of Pathology, Leiden University Medical Center, ZA LEIDEN 2333, The Netherlands; ${ }^{14}$ Departments of Human and Clinical Genetics, Leiden University Medical Center, ZA LEIDEN 2333, The Netherlands; ${ }^{15}$ Laboratory of Molecular Medicine, Human Genome Center, Institute of Medical Science, The University of Tokyo, Tokyo, Japan; ${ }^{16}$ Department of Gastroenterology, Institut de Malalties Digestives i Metabòliques, Hospital Clínic, Centro de Investigación Biomédica en Red de Enfermedades Hepáticas y Digestivas (CIBERehd), IDIBAPS, University of Barcelona, Barcelona, Catalonia, Spain; ${ }^{7}$ Fundacion Publica Galega de Medicina Xenomica (FPGMX), CIBERER, Genomic Medicine Group-University of Santiago de Compostela, Santiago de Compostela, Galicia, Spain; ${ }^{18}$ The University of Hong Kong, Pokfulam Road, Hong Kong, China; ${ }^{19}$ Department of Genetics, University Medical Center Groningen, University of Groningen, P.O. Box 30.000 I. Groningen 9700 RB, the Netherlands; ${ }^{20}$ Institute of Experimental Medicine, Academy of Sciences of the Czech Republic, Videnska 1083, 14200 Prague 4, Czech Republic; ${ }^{21}$ Division of Clinical Epidemiology and Aging Research, German Cancer Research Center, Im Neuenheimer Feld 280, Heidelberg 691 20, Germany; ${ }^{22}$ Department of General Internal Medicine, University Hospital, Schleswig-Holstein, Campus Kiel, Schittenhelmstraße 12, Kiel 24l05, Germany; ${ }^{23}$ POPGEN Biobank, University Hospital Schleswig-Holstein, Campus Kiel, Schittenhelmstrasse 12, Kiel 24105, Germany; ${ }^{24}$ Department of General and Thoracic Surgery, University Hospital Schleswig-Holstein, Campus Kiel, Arnold-Heller-Strasse 3, Kiel 24 105, Germany; ${ }^{25}$ Institut für Community Medicine, University Hospital Greifswald, Walther-Rathenau-Strasse 48, Greifswald 17487, Germany; ${ }^{26}$ Klinik für Innere Medizin A University Hospital Greifswald, Friedrich-Loeffler-Strasse 23a, Greifswald 17487, Germany; ${ }^{27}$ Klinik für Innere Medizin C, University Hospital Greifswald, Ferdinand-Sauerbruch-Strasse, Greifswald 17487 , Germany; ${ }^{28}$ IDIBELL-Catalan Institute of Oncology and University of Barcelona, Av Gran Via 199, L'Hospitalet, Barcelona 08907, Spain; ${ }^{29}$ Centre for Research in Environmental Epidemiology (CREAL), Municipal Institute of Medical Research (IMIM-Hospital del Mar) and CIBER Epidemiología y Salud Pública (CIBERESP), Doctor Aiguader, Barcelona 88 E-08003, Spain; ${ }^{30}$ Fondazione IRCCS Istituto Nazionale Tumori, and Fondazione IFOM, Istituto FIRC di Oncologia Molecolare, Milan, Italy; ${ }^{3 l}$ Departamento de Biología, Universidad del Tolima, Barrio Altos de Santa Helena, Ibague, Tolima, Colombia; ${ }^{32}$ Departamento de Patología, Hospital Pablo Tobon Uribe, Calle 78 B No. 69-240, Medellín, Colombia; ${ }^{33}$ Faculty of Health, School of Biomedical Sciences, University of Newcastle, NSW, Australia; ${ }^{34}$ Section of Cancer Genetics, Institute of Cancer Research, 15 Cotswold Rd, Sutton, Surrey SM2 5NG, UK

It is now recognised that a part of the inherited risk of colorectal cancer (CRC) can be explained by the co-inheritance of low-penetrance genetic variants. The accumulated experience to date in identifying these variants has served to highlight difficulties in conducting statistically and methodologically rigorous studies and follow-up analyses. The COGENT (COlorectal cancer GENeTics) consortium includes 20 research groups in Europe, Australia, the Americas, China and Japan. The overarching goal of COGENT is to identify and characterise low-penetrance susceptibility variants for CRC through association-based analyses. In this study, we review the rationale for identifying low-penetrance variants for CRC and our proposed strategy for establishing COGENT.

British Journal of Cancer (2010) I 02, 447-454. doi:I0.1038/sj.bjc.6605338 www.bjcancer.com

Published online 17 November 2009

(C) 2010 Cancer Research UK

Keywords: colorectal cancer; association; polymorphism

*Correspondence: Professor RS Houlston, Section of Cancer Genetics, The Institute of Cancer Research, Brookes Lawley Building, Haddow Laboratories, 15 Cotswold Road, Sutton, Surrey SM2 5NG, UK; E-mail: Richard.Houlston@icr.ac.uk

Received 10 June 2009; revised 3 September 2009; accepted 3 September 2009; published online 17 November 2009 


\section{BACKGROUND}

Although inherited susceptibility underlies $\sim 35 \%$ of variance in colorectal cancer (CRC) risk (Lichtenstein et al, 2000), highpenetrance germline mutations account for $<6 \%$ of cases (Aaltonen et al, 2007). Much of the remaining variation in genetic risk is likely to be a consequence of the co-inheritance of multiple low-penetrance variants, some of which are common.

The 'common-disease common-variant' model of CRC implies that association analyses based on scans of polymorphic variants should be a powerful strategy for identifying low-penetrance susceptibility alleles. This assertion has recently been vindicated by genome-wide association (GWA) studies, which have provided robust evidence for several common low-risk variants influencing CRC risk (Tomlinson et al, 2005, 2007; Broderick et al, 2007; Zanke et al, 2007; Houlston et al, 2008; Jaeger et al, 2008; Tenesa et al, 2008). Although the risk of CRC associated with each of these common variants is individually modest, they make a significant contribution to the overall disease burden by virtue of their high frequencies in the population. Moreover, by acting in concert with each other, they have the potential to significantly affect an individual's risk of developing CRC. Hence, this class of susceptibility alleles is potentially of public health importance, allowing risk stratification within populations. One benefit for risk prediction between population subgroups is that it could enable tailoring of the invasiveness or frequency of large bowel screening, eventually leading to a reduction in mortality and even incidence through secondary prevention. Finally, the identification of new risk variants may identify new cancer pathways that made lead, in time, to the development of new prevention or treatment strategies for CRC.

To facilitate the study of predisposition to CRC, we established COGENT (COlorectal cancer GENeTics), an international consortium with the goal of identifying and characterising low-penetrance genetic variants that predispose to CRC. In this study, we review the rationale for studying low-penetrance susceptibility to CRC and our proposed strategy for COGENT.

\section{Difficulties in conducting methodologically rigorous association studies}

To date, most association studies based on the candidate gene approach have only evaluated a restricted number of polymorphisms, primarily in genes implicated in the metabolism of dietary carcinogens and protection of DNA from carcinogen-induced damage. Reports from these studies have largely been disappointing, with numerous positive associations initially from analyses of small case-control series being unconfirmed by subsequent analyses. Only a minority of studies have reported case-control data on the same variants, allowing pooling of data (Table 1). Although $P$-values from meta-analyses of such studies provide limited support for the role of variants in MTHFR (Huang et al, 2007; Hubner and Houlston, 2007), CCND1 (Tan et al, 2008),
GSTT1 (de Jong et al, 2002), XPC (Zhang et al, 2008), NQO1 (Chao et al, 2006) and NAT2 (Chen et al, 2005), such analyses should be interpreted with caution even if publication bias is ignored. Use of false-positive report probability value (FPRP) (Wacholder et al, 2004), which integrates the earlier probability for association and statistical power, provides one method for assessing the robustness of summary estimates derived from pooled analyses. Although earlier probabilities are partly subjective, influenced by previous findings and experimental evidence with regard to the known impact of variants, the earlier probability for variants in candidate genes is unlikely to be better than 1 in 1000 (or 0.001) (Thomas and Clayton, 2004). Imposing a 'best case' value less than 0.001 and stipulating an odds ratio of 1.2 for associations, it is noteworthy that the likelihood of any of the variants being associated with CRC risk is not high (i.e., FPRP $>0.2$ suggested to be appropriate for summary analyses (Wacholder et al, 2004)). Hence, despite much research, until the advent of GWA studies, few, if any, definitive susceptibility alleles for CRC have been unequivocally identified through association studies. The accumulated experience to date has served to highlight the difficulties in conducting statistically and methodologically rigorous association studies to identify new cancer predisposition loci. The main issues are summarised below:

1. The increase in CRC risk conferred by any common polymorphic variant is almost certainly small (i.e., typical relative risk $\sim 1.2$ ). The inherent statistical uncertainty of case-control studies involving just a few hundred cases and controls severely constrains study power to reliably identify genetic determinants conferring modest, but potentially important, risks.

2. As of the large number of polymorphisms in the genome, falsepositive associations are inevitably more frequent than truepositive associations when testing large numbers of generic markers (especially when using off-the-shelf SNP arrays), even if studies are conducted in a scientifically rigorous manner. Hence, associations need to attain a high level of statistical significance to be established beyond reasonable doubt. For this reason, in GWA studies, a $P$-value threshold of $5.0 \times 10^{-7}$ has been advocated and is generally considered to be appropriate for genome-wide significance.

3. Positive associations need to be replicated in independent case-control series to further limit the type 1 error rate. However, to increase power, the allelic architecture of the population from which these case-control series are ascertained needs to have similar ancestry and, ideally, the same linkage disequilibrium (LD) structure.

4. It should be recognised that cancers such as CRC are somewhat heterogeneous with respect to aetiology and biology. Specifically for CRC, colonic and rectal disease may have different risk factors and have a varied spectrum of somatic mutations and epimutations. It must thus be recognised that a given variant may not affect the risk of all histological forms of CRC.

Table I Polymorphisms reported to be statistically significant in meta-analyses

\begin{tabular}{|c|c|c|c|c|c|c|c|}
\hline Polymorphism & Risk group & $\begin{array}{l}\text { MAF/at risk } \\
\text { frequency }\end{array}$ & OR $(95 \% \mathrm{Cl})$ & $P$-value & $\begin{array}{c}\text { No } \\
\text { studies/cases }\end{array}$ & $\begin{array}{l}\text { Power, } \\
\text { OR = I.2 }\end{array}$ & $\begin{array}{c}\text { FPRP @ } \\
\text { prior of } 0.001\end{array}$ \\
\hline CCND I-G870A & GA vs GG & $0.12-0.64$ & $1.18(1.06-1.32)$ & 0.0031 & $12 / 46 \mid 4$ & $61 \%$ & 0.86 \\
\hline MTHFR AI298C & $C C$ vs $C A+A A$ & $0.29-0.22$ & $0.81(0.69-0.96)$ & 0.012 & |4/4764 & $37 \%$ & 0.98 \\
\hline NAT-acetylator & Rapid vs slow & $0.32-0.77$ & $1.08(1.00-1.16)$ & 0.04 & |8/674| & $99 \%$ & 0.97 \\
\hline NQO I-Prol87Ser & $\mathrm{CT}+\mathrm{T}$ vs $\mathrm{CC}$ & $0.11-0.23$ & $1.18(1.02-1.35)$ & 0.02 & $5 / 1637$ & $60 \%$ & 0.96 \\
\hline
\end{tabular}

Abbreviations: $\mathrm{Cl}=$ confidence interval; FPRP = false-positive report probability; $\mathrm{MAF}=$ minor allele frequency; OR =odds ratio. Adapted from Dong et al (2008) and Hubner and Houlston. 
The power of any analysis stratified by histology is therefore limited because of the smaller numbers of cases in each group.

5. Careful attention must be paid to population stratification as a source of confounding, because cancer rates and allele frequencies vary with race/ethnicity. This is one possible explanation for some of the false-positive associations reported in literature.

6. Epidemiological risk factor data should ideally be taken into consideration to allow the examination of interactions between known aetiological factors (e.g., dietary risk factors) and genetic risk variants. As very large sample sizes are probably needed to detect interactions, the power of these types of analyses in the association studies reported to date has been extremely limited.

7. Rare germline polymorphisms may be more highly penetrant and have significance for individuals, although the populationattributable risk may be low. Extreme examples include the previously identified mutations in DNA repair enzymes and Lynch Syndrome. Only through genotyping and sequencing of large numbers of individuals can additional rare variants that confer important individual risk be identified. Advances in sequencing technology make this feasible.

\section{Characteristics of low-penetrance variants}

Most studies aimed at identifying low-penetrance alleles for cancer susceptibility have been based on a candidate gene approach formulated on preconceptions of pathology pertaining to the role of specific genes in the development of CRC. However, without a clear understanding of the biology of predisposition, the choice of suitable genes for the disease is inherently problematic, and very few susceptibility loci for CRC have been identified that adopt this strategy. An unbiased approach to genetic analysis is therefore required.

The availability of high-resolution LD maps and hence of comprehensive sets of tagging SNPs that capture most of the common sequence variation allows GWA studies for disease associations to be efficiently conducted. This approach is agnostic in that it does not depend on previous knowledge of function or presumptive involvement of any gene in disease causation. Moreover, it minimises the probability of failing to identify important common variants in hitherto unstudied loci (i.e., genes and regulatory regions).

Three GWA studies of CRC have so far been reported and 10 independent loci shown conclusively to be associated with CRC risk: 8q24.21, 11q23, 18q21.1 (SMAD7), 8q23.1 (EIF3H), 15q (GREM1), 19q13.1 (RHPN2), 20q12.3, 14q22.2 (BMP4), 16q22.1 $(C D H 1)$ and 10p14 (Tomlinson et al, 2005, 2007; Broderick et al, 2007; Zanke et al, 2007; Houlston et al, 2008; Jaeger et al, 2008; Tenesa et al, 2008). Risks associated with each of the common variants at each of these loci are modest (ORs 1.1-1.3; Table 2) and there is little evidence of interactive effects. With homozygous risk variants conferring twice the heterozygote risk, the distribution of risk alleles follows a normal distribution in both case and controls, with a shift towards a higher number of risk alleles in affected individuals consistent with a polygenic model of disease predisposition (Figure 1A). Figure 1B shows the ORs relative to the median number of risk alleles. Individuals with $15+$ risk alleles have at least a three-fold increase in risk compared with those with a median number of risk alleles.

Data from these GWA studies and results from similar gene discovery efforts in other tumours are proving to be highly informative with regard to the allelic architecture of cancer

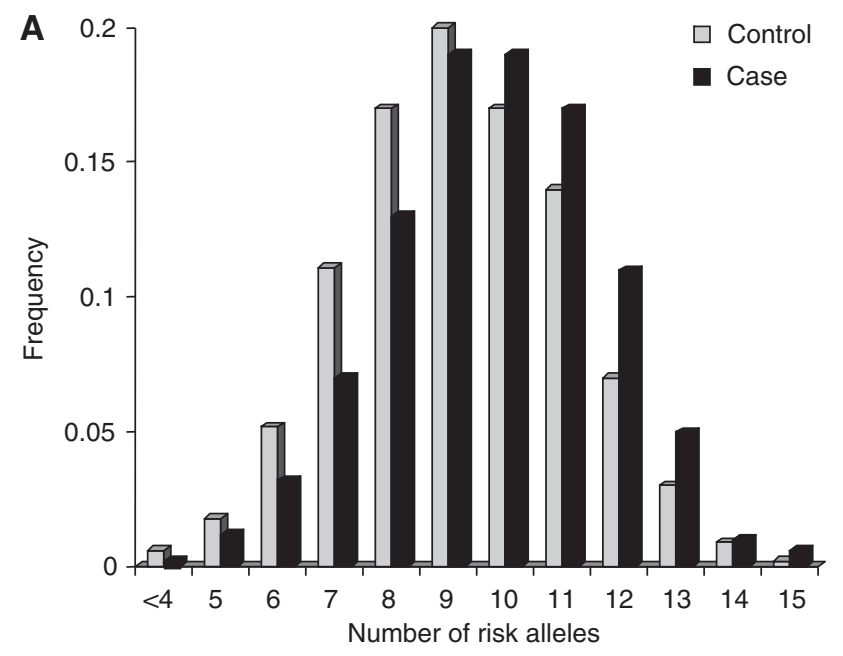

B

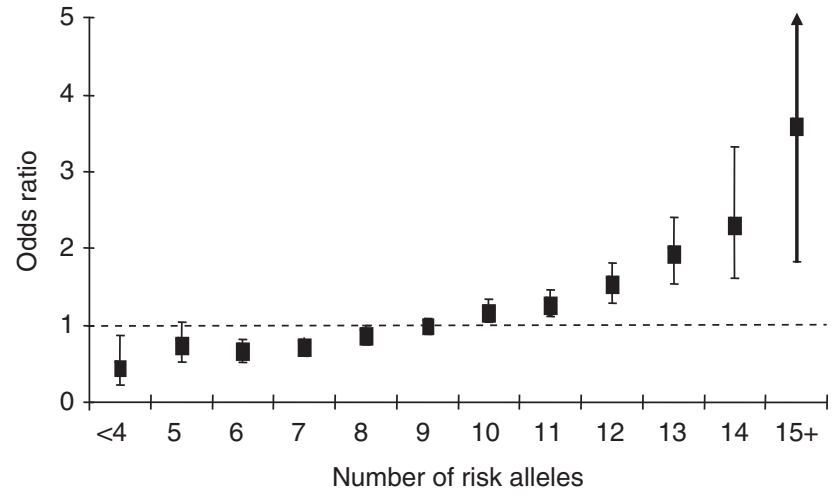

Figure I Polygenic model of colorectal cancer susceptibility. (A) Distribution of risk alleles for CRC, cases (black bars) and controls (grey bars); (B) Plot of the increasing ORs for CRC with increasing number of risk alleles. The ORs are relative to the median number of risk alleles; Vertical bars correspond to $95 \%$ confidence intervals. Data from Houlston et al (2008)

Table 2 The 10 loci associated with colorectal cancer risk identified from GWA studies (Tenesa and Dunlop, 2009)

\begin{tabular}{|c|c|c|c|c|c|}
\hline Gene/locus & Chromosome & SNP & $\begin{array}{l}\text { Effect size } \\
\text { (odds ratio) }\end{array}$ & $\begin{array}{c}\text { Allele } \\
\text { frequency }\end{array}$ & $\begin{array}{l}\text { Population } \\
\text { attributable risk (\%) }\end{array}$ \\
\hline - & $8 q 24$ & rs6983267 & $1.21(1.15-1.27)$ & 0.51 & 9.7 \\
\hline- & 11 q23 & rs3802842 & $1.12(1.07-1.17)$ & 0.29 & 3.4 \\
\hline EIF3H & $8 q 23$ & rs 16892766 & $1.25(1.19-1.32)$ & 0.07 & 1.7 \\
\hline - & $10 p \mid 4$ & rs 10795668 & $1.12(1.10-1.16)$ & 0.67 & 7.4 \\
\hline RHPN2 & $19 q 13$ & rs 10411210 & $1.15(1.10-1.20)$ & 0.90 & 11.9 \\
\hline BMP2 & $20 q 12$ & rs961253 & $1.12(1.08-1.16)$ & 0.35 & 4.0 \\
\hline
\end{tabular}

Abbreviation: GWA = genome-wide association. 
susceptibility in general. The number of common variants that account for more than $1 \%$ of inherited risk is very low and only a small proportion of the heritability of any cancer can be explained by currently identified loci. Estimates of the contribution of currently identified loci to excess familial risk of CRC may be conservative, as there may be imperfect tagging surrogates for true aetiological loci. Multiple causal variants may also exist at each locus, including low-frequency variants with significantly larger cumulative effects on risk. Few of the observed disease-associated variants are coding variants, with many of the loci mapping to regions bereft of genes or protein-encoding transcripts. It is likely that much of the common variation in cancer risk is mediated through sequence changes influencing gene expression, perhaps in a subtle manner, or through effects on pathway components mitigated by functional redundancy.

\section{FUTURE DIRECTIONS}

\section{Prospects for identifying additional common variants}

The power of existing GWA studies to identify common alleles conferring risks of 1.2 or greater (such as the $8 \mathrm{q} 24$ variant) is high. Hence, there are unlikely to be many additional CRC SNPs with similar effects for alleles with frequencies $>0.2$ in populations of European ancestry. Recent studies have had low power to detect alleles with smaller effects and/or MAFs $<0.1$. By implication, variants with such profiles are likely to collectively confer substantial risk because of their multiplicity or sub-maximal LD with tagging SNPs. The tagging SNPs used for GWA studies capture on an average $\sim 80 \%$ of common SNPs in the European population (i.e., $r^{2}>0.8$ ), but only $\sim 12 \%$ of SNPs with MAFs of $5-10 \%$ are tagged at this level, limiting the power to detect this class of susceptibility allele. GWA-based strategies are not configured optimally to identify low-frequency variants with potentially stronger effects or to identify recessively acting alleles. Nor are current arrays formatted ideally to capture copy number variants or other structural variants such as small-scale insertions or deletions, which may affect CRC risk. It is therefore highly likely that a large number of low-penetrance variants remain to be discovered. This assertion is supported by the continued excess of associations observed over those expected in studies reported to date. Further efforts to expand the scale of GWA meta-analyses, in terms of both sample size and SNP coverage, and to increase the number of SNPs taken forward to large-scale replication may identify additional variants for CRC.

Analyses of most GWA studies have so far been primarily directed towards identifying single locus SNP associations. It is possible that analyses based on haplotypes of markers may identify 'rarer' disease alleles that may be present on rare haplotypes missed by single SNP analyses. Under certain circumstances, especially in which interaction effects are large and main effects are small, gene-gene interactions may be detected where no locus with a main effect has been identified (Marchini et al, 2005). Multilocus approaches may therefore be the focus of future experiments as they may yield greater power to detect associations under certain genetic models.

\section{Identifying causal variants}

Validated tagSNPs are highly unlikely to directly cause CRC. Identifying the causal variant from a tagSNP that is statistically associated with disease is difficult. Although blocks of LD allow the efficient survey of the genome, they hamper fine mapping of the disease-associated region. Different ethnic groups are likely to have different LD block patterns and they can therefore be used to refine the location of a disease susceptibility locus before resequencing and functional analyses. The usefulness of this approach depends on the size of the study and SNP allele frequencies in different ethnic groups. In some of these populations, lower environmental risk exposure with lower CRC, incomplete case ascertainment and recording tools, as well as absence of large sample sets, are other challenges.

\section{Incorporating non-genetic risk factors into risk models}

Colorectal cancer risk will probably be determined by complex interactions between the various genetic and lifestyle/dietary risk factors. Epidemiological studies have established several dietary risk factors for colorectal neoplasia; these include low vegetable and high meat consumption (especially processed meat), and micronutrient deficiency and excessive alcohol intake. There is a weaker association between CRC, smoking and lack of physical activity. Common genetic variants are likely to interact with these environmental-lifestyle risk factors to modify risk. Furthermore, common gene variants will have a role in determining the effectiveness of chemoprevention agents such as non-steroidal anti-inflammatory drugs, hormone replacement therapy and micronutrient supplementation.

In assessing the interplay between inherited and non-genetic risk factors, analyses using different population cohorts will be highly informative. Wider comparisons between the population genetics of different ethnic groups have shown that SNP allele frequencies can vary greatly among ethnic groups, principally as a result of founder effects and genetic drift. Indeed, some SNPs may be informative in one population and not in another. At least in principle and probably in practice, some variants may have stronger or weaker effects on disease, depending on environment or general genetic background, as observed in inbred lines of mice.

Identification of the interaction between genetic variants and environmental risk factors is contingent on very large data sets ideally from different population cohorts, something only achievable through multi-centre collaborations. Even with such collaborative efforts, incorporating environmental risk factor data into models of predisposition is likely to be a serious challenge as, although ethnicity can be defined through genotype, environmental background is harder to standardise.

\section{Inherited prognostic and predictive variants}

In addition to influencing the risk of developing CRC, inherited genetic host factors are likely to influence the natural course of the disease. As a potential prognostic factor, the concept of germline variation imparting inter-individual variability in tumour development, progression and metastasis is receiving increasing attention. Compared with breast cancer, studies of the impact of germline variation on CRC prognosis have been more limited. Prognostic studies have generally examined the same candidate genes that are considered to have a role in predisposition. Genetic variation affecting inter-individual disease expression may influence the later stages of malignancy rather than early events associated with an inherited predisposition. Variants in growth factor, apoptosis or immune surveillance signalling pathways, for instance, might not cause CRC initiation but could have a substantial effect on the outcome of established disease. Chemotherapy response and toxicity may be related to germline genotype. Linking GWA data to patient outcome provides an attractive strategy for identifying new prognostic markers. It is essential to impose appropriate statistical thresholds and conduct replication analyses to avoid reporting false positives.

\section{RATIONALE FOR THE COGENT CONSORTIUM}

The recognition that low-penetrance alleles contribute to the inherited risk of CRC represents a major advance in our 
Table 3 Number of CRC cases and controls currently established by COGENT consortium members

Number of

subjects

\section{European}

Study name

Institute of Cancer Research, UK NSCCG (National Study of Colorectal Cancer) (Penegar et al, 2007)

Edinburgh University, UK

Oxford University, UK

Cambridge University, UK

Barcelona and Santiago, Spain Barcelona, Spain

University of Helsinki, Finland

Karolinska Institute, Sweden

German Cancer Research Centre (DKFZ): on behalf of German HNPCC consortium

University of Keil and

Greifswald, Germany

German Cancer Research

Centre

Institute of Experimental

Medicine, Academy of Science,

Czech Republic

University of Groningen, the Netherlands

University of Leiden, the

Netherlands

Fondazione IRCCS Istituto

Nazionale Tumori, Milan, Italy

Australia

Ludwig Institute for Cancer

Research, Melbourne

The University of Newcastle, Hunter Family Cancer Service

New South Wales (Porteous et al, 2003)

SOCCS (Scottish Colorectal Cancer Study)

(Theodoratou et al, 2008)

Consortium) (Kemp et al, 2006)

VICTOR - post-treatment stage of a Phase III, potentially curative therapy (Kerr et al, 2007)

QUAZAR2 - multicentre international study of Cancer Hereditary) tros determinantes ambientales, genéticos y moleculares del cáncer colorectal en España) Bellvitge Case-Control Study Study) (Salovaara et al, 2000)

POPGEN (Population Genetic Cohort) from (Volzke et al, 2005)

SCOPE study (de Jong et al, 2005)

Victorian Cancer Biobank
COGS (Colorectal Cancer Genetics Susceptibly Study)

CORGI (Colorectal Tumour Gene Identification randomised double-blind, placebo-controlled study of rofecoxib $(\mathrm{VIOXX})$ in colorectal cancer patients after capecitbine+/-bevacizumab as adjuvant treatment of CRC SEARCH (Studies of Epidemiology and Risk Factors in

EPICOLON Consortium (Castells and Andreu, 2007) ENTERICOS (Disinfection by-products and other Environmental, genetic and molecular determinants of colorectal cancer - subproductos de la desinfección y FCCPS (Finnish Colorectal Cancer Predisposition

German HNPCC consortium (Frank et al, 2008) Schleswig-Holstein, north Germany (Krawczak et al, 2006; Schafmayer et al, 2007). SHIP (Survey of Health in Pommerania) from east and north-east Germany

ESTHER (Epidemiologische Studie zu Chancen der Verhütung, Früherkennung und optimierten Therapie chronischer Erkrankungen in der älteren Bevölkerung) from the Hunter Region of New South Wales

Population-based study; South-eastern Finland
Population-based biobank project

Population-based collection of cases and controls

\section{General setting}

Population-based UK study. Spouse controls from NSCCG (Penegar et al, 2007) and GELCAPS (Genetic Lung Cancer Predisposition Study)

(Eisen et al, 2008)

Population-based incident case series aged $<55$ at diagnosis. Population-based controls

Population-based incident case series; Scotland, UK

Cases with family history of CRC ascertained through clinical genetics centres in the UK. Spouse controls with no personal or family history of CRC Samples from a closed clinical trial

UK blood donors

Popul

Population-based case-control study; Spain Case-control study of CRC to evaluate the increased risk associated with chronic DBP exposure through ingestion, inhalation and dermal absorption

Unselected cases ascertained through 12 hospitals 3000 3000 Örebro health-care regions in Sweden. Blood donor controls

Familial non-HNPCC cases recruited through German HNPCC consortium, principally through six hospitals of Bochum, Bonn, Dresden,

Düsseldorf, Heidelberg and Munich/Regensburg.

Controls: unrelated and ethnicity- and age-matched blood donors recruited by the Institute of

Transfusion Medicine and Immunology, Faculty of Mannheim, Germany

Population-based biobank projects

Population-based biobank project

Unselected CRC cases mainly recruited from nine

Liberec, Ples, Pribram, Usti nad Labem and Zlin)

(Tulupova et al, 2008). Controls hospital patient and blood donors

Unselected CRC cases, hospital patient controls

from the Netherlands

Unselected CRC cases. Controls ascertained through genetic testing programmes for noncancer-related conditions

Unselected CRC cases, population controls 


\begin{tabular}{|c|c|c|c|c|}
\hline \multirow[b]{2}{*}{ European } & \multirow[b]{2}{*}{ Study name } & \multirow[b]{2}{*}{ General setting } & \multicolumn{2}{|c|}{$\begin{array}{l}\text { Number of } \\
\text { subjects }\end{array}$} \\
\hline & & & Cases & Controls \\
\hline \multicolumn{5}{|l|}{ The Americas } \\
\hline $\begin{array}{l}\text { Ibague, Colombia. } \\
\text { Universidad del Tolima }\end{array}$ & & Unselected CRC cases, population-based controls & 500 & 700 \\
\hline Toronto, Canada & $\begin{array}{l}\text { OFCCR (Ontario Familial Colorectal Cancer Registry) } \\
\text { (Cotterchio et al, 2000) }\end{array}$ & Population-based case-control study; Ontario & 1257 & 1336 \\
\hline \multicolumn{5}{|l|}{ Asia } \\
\hline $\begin{array}{l}\text { University Hong Kong } \\
\text { Medical Centre, China }\end{array}$ & UHKMC series & Unselected CRC cases, hospital patient controls & 2000 & 2000 \\
\hline University of Tokyo, Japan & Biobank Japan & Population-based biobank project & 6000 & 6000 \\
\hline Total & & & 49308 & 46804 \\
\hline
\end{tabular}

Abbreviations: COGENT = COlorectal cancer GENeTics; CRC = colorectal cancer .

understanding. In view of the above-noted issues, over the last few years, collaborations have been steadily developing between groups in the United Kingdom, Canada, the Americas, Holland, Germany, Finland, Spain and Australia that are engaged in ongoing searches for low-penetrance CRC variants through association-based studies. What initially began from relatively loose affiliations centred around work on specific projects has begun to crystallise into a more formal collaborative network after replication analyses of two published GWA studies. To continue and expand collaboration, a meeting was held at the University of Leiden, the Netherlands, in January 2009 to review ongoing association studies. There assembled an international team of researchers with expertise encompassing genetic epidemiology, statistical genetics, gene mapping, biology, molecular genetics, pathology and diagnosis and clinical management of CRC.

There was a consensus among participants that many of the challenges inherent in this field can best be addressed by international cooperative efforts, and the group unanimously decided to establish a CRC association consortium. An invitation to join COGENT that was subsequently extended to other groups known to be performing CRC association studies was well received. At present, 20 groups that are performing case-control genetic association studies have joined COGENT (Table 3). The eligibility criterion for inclusion is the involvement in a case-control study based on at least 500 cases and 500 controls sampled from the same population. The sample size limit aims to ameliorate the potential statistical, biological and technological/methodological confounding effects of small sample sizes (Moonesinghe et al, 2008). Collectively, over 48000 cases and 43000 controls have so far been accrued by COGENT researchers (Table 3 ).

In each of the study centres, collection of samples and of clinicopathological information has been undertaken with informed consent and relevant ethical review board approval in accordance with the tenets of the Declaration of Helsinki. Material transfer agreements have already been used between partners to allow for sharing of individualised data, and similar procedures will be adopted for future collaborative work.

Data pooling provides a very cost-effective approach to achieve an adequate power for subgroup analyses, which are unlikely to have sufficient sample sizes in a single study. Several potential problems need to be considered at the stage of data pooling. Given that individual studies have different data formats, covariates from individual studies will be agreed upon and compiled into a common set of variables relevant to specific projects. Study data sets sent from different centres will be checked for outliers, aberrant distribution, inadmissible values and inconsistencies before pooling to ensure data accuracy. Systematic variation between centres in terms of genotyping will be assessed globally using principal components and on a per-SNP basis. Discrepancies can be cross-verified with study centres.

COGENT represents the first international collaborative study seeking to comprehensively understand the impact of lowpenetrance susceptibility to CRC and to describe the genetic landscape of the disease. The immediate goal of the group is to work together collaboratively to study polymorphisms that were previously associated with CRC risk and to plan for future highquality studies. Past productive collaboration has laid the groundwork for these future studies centred initially on the expansion of discovery and replication of GWA studies, with biological analyses of variants and epidemiological studies as longer-term aims.

\section{ACKNOWLEDGEMENTS}

The work of UK groups is supported by grants from Cancer Research UK and the European Union. In Spain, work is supported by grants from the Instituto de Salud Carlos III, grants FIS 05/1006, 08/1359, 08/1635 and European Commission FP6 Food-CT-2006036224 (VM). In Canada, work is supported by grants from Genome Canada (the ARCTIC Project), the National Cancer Institute of Canada (the CaRE Project) and the Ontario Institute for Cancer Research. In Finland, work is supported by grants from Academy of Finland (Finnish Centre of Excellence Program 20062011), the Sigrid Juselius Foundation, the Finnish Cancer Societies and by the European Union. The work of DFKS is supported by the German Genome Network (NGFNplus). In the Czech Republic, work is supported by GACR 310/07/1430. In Sweden, work is supported by grants from the Swedish Cancer Foundation and the Swedish Research Council. In Barcelona and Santiago (Epicolon), work is supported by grants from Fondo de Investigación Sanitaria (FIS 04/1126, 05/2031, 05/0071, 08/0025, 08/1276), Xunta de Galicia (PGIDIT07PXIB9101209PR), Fundación de Investigación Médica Mutua Madrileña (CRP and SCB), Ministerio de Educación y Ciencia (SAF 07-64873), Asociación Española contra el Cáncer, Fundación Olga Torres (SCB) and Acción Transversal contra el Cáncer (Instituto de Salud Carlos III). CIBERER and CIBEREHD are funded by the Instituto de Salud Carlos III. SCB is supported by a contract from the Fondo de Investigación Sanitaria (CP 03-0070, Ministerio de Sanidad. Provision of genotyping is gratefully provided by Santiago de Compostela node of the Spanish National Genotyping Center (CeGen). In The Netherlands, work of RH is supported by the Dutch Cancer Society and the European Community, and the work of JTW, TvW, HM and PD is supported 
by the Dutch Cancer Society (UL2005-3247) and Fonds NutsOhra. In Hong Kong, work is supported by grants from the Michael and Betty Kadoorie Cancer Genetics Research Programme II and by the Bobby Moore Fund of Cancer Research UK. Work in Australia is conducted under the auspices of the Hilton Ludwig Cancer Metastasis Initiative and supported by a grant from the NHMRC (Project Grant 489418). In Japan, this work was conducted as a part of the BioBank Japan Project that was supported by the Ministry of Education, Culture, Sports, Sciences and Technology of the Japanese government. The ESTHER and VERDI studies are supported by grants from the Baden Württemberg Ministry of Research, Science and Arts and the German Cancer Aid (Deutsche Krebshilfe, Grant M24/95/BR I). The Kiel cohort (POPGEN) is funded through the German Ministry of Education and Reserach through the POPGEN Biobank grant and the Colon Cancer Network of the German National Genome Research Network. SHIP is part of the Community Medicine Research net of the University of Greifswald, Germany, which is funded by the Federal Ministry of Education and Research, the Ministry of Cultural Affairs, as well as by the Social Ministry of the Federal State of Mecklenburg-West Pomerania. Genome-wide data have been supported by the Federal Ministry of Education and Research (Grant no. 03ZIK012) and by a joint grant from Siemens Healthcare, Erlangen, Germany and the Federal State of Mecklenburg-West Pomerania. The University of Greifswald is a member of the 'Center of Knowledge Interchange' program of Siemens AG. MME, AV and LC-C have received funding from
Cancer Research UK and Universidad del Tolima. In Italy, collection of samples and clinical data of individuals recruited at Fondazione IRCCS, Istituto Nazionale Tumori was possible because of efforts by Lucio Bertario, Paola Sala, Silvia Veneroni, Manuela Gariboldi, Fernando Ravagnani, Tiziana Camerini, Maria Gaetana Di Mauro, Maria Grazia Daidone and Marco A Pierotti. This study is supported by grants from Associazione/Fondazione Italiana per la Ricerca sul Cancro (AIRC/FIRC) and Lega Italiana per la Lotta ai Tumori.

\section{URLs}

Epidemiologische Studie zu Chancen der Verhütung, Früherkennung und optimierten Therapie chronischer Erkrankungen in der älteren Bevölkerung (ESTHER) - http://www.esther.dkfz.org/esther/).

Studies of Epidemiology and Risk Factors in Cancer Heredity (SEARCH) - http://www.srl.cam.ac.uk/search/Homepage.htm

QUASAR - http://www.octo-oxford.org.uk/alltrials/trials/q2.html).

ENTERICOS - http://www.hiwate.eu/news/entericos-case-controlstudy-colon-cancer-spain-receives-extra-funding-spanish-ministyhealth-c

Biobank Japan - http://www.src.riken.go.jp/english/project/person/ index.html

Victorian cancer biobank - http://www.viccancerbiobank.org.au/

National Study of Colorectal Cancer Genetics (NSCCG) - http:// www.icr.ac.uk/research/research_sections/cancer_genetics/cancer_ genetics_teams/molecular_and_population_genetics/nsccg/index. shtml

\section{REFERENCES}

Aaltonen L, Johns L, Jarvinen H, Mecklin JP, Houlston R (2007) Explaining the familial colorectal cancer risk associated with mismatch repair (MMR)-deficient and MMR-stable tumors. Clin Cancer Res 13: 356-361 Broderick P, Carvajal-Carmona L, Pittman AM, Webb E, Howarth K, Rowan A, Lubbe S, Spain S, Sullivan K, Fielding S, Jaeger E, Vijayakrishnan J, Kemp Z, Gorman M, Chandler I, Papaemmanuil E, Penegar S, Wood W, Sellick G, Qureshi M, Teixeira A, Domingo E, Barclay E, Martin L, Sieber O, Kerr D, Gray R, Peto J, Cazier JB, Tomlinson I, Houlston RS (2007) A genome-wide association study shows that common alleles of SMAD7 influence colorectal cancer risk. Nat Genet 39: 1315-1317

Castells A, Andreu M (2007) EPICOLON project: contribution to the knowledge of Lynch syndrome and other familial or hereditary colorectal cancer. Med Clin (Barc) 128: 55-60

Chao C, Zhang ZF, Berthiller J, Boffetta P, Hashibe M (2006) NAD(P)H:quinone oxidoreductase 1 (NQO1) Pro187Ser polymorphism and the risk of lung, bladder, and colorectal cancers: a meta-analysis. Cancer Epidemiol Biomarkers Prev 15: 979-987

Chen K, Jiang QT, He HQ (2005) Relationship between metabolic enzyme polymorphism and colorectal cancer. World J Gastroenterol 11: 331-335

Cotterchio M, McKeown-Eyssen G, Sutherland H, Buchan G, Aronson M, Easson AM, Macey J, Holowaty E, Gallinger S (2000) Ontario familial colon cancer registry: methods and first-year response rates. Chronic Dis Can 21: $81-86$

de Jong MM, Nolte IM, te Meerman GJ, van der Graaf WT, de Vries EG, Sijmons RH, Hofstra RM, Kleibeuker JH (2002) Low-penetrance genes and their involvement in colorectal cancer susceptibility. Cancer Epidemiol Biomarkers Prev 11: 1332-1352

de Jong MM, Nolte IM, Te Meerman GJ, van der Graaf WT, Mulder MJ, van der Steege G, Bruinenberg M, Schaapveld M, Niessen RC, Berends MJ, Sijmons RH, Hofstra RM, de Vries EG, Kleibeuker JH (2005) Colorectal cancer and the CHEK2 1100delC mutation. Genes Chromosomes Cancer 43: 377-382

Dong LM, Potter JD, White E, Ulrich CM, Cardon LR, Peters U (2008) Genetic susceptibility to cancer: the role of polymorphisms in candidate genes. JAMA 299: 2423-2436

Eisen T, Matakidou A, Consortium G, Houlston R (2008) Identification of low penetrance alleles for lung cancer: the GEnetic Lung CAncer Predisposition Study (GELCAPS). BMC Cancer 8: 244

Frank B, Burwinkel B, Bermejo JL, Forsti A, Hemminki K, Houlston R, Mangold E, Rahner N, Friedl W, Friedrichs N, Buettner R, Engel C, Loeffler M, Holinski-Feder E, Morak M, Keller G, Schackert HK,
Kruger S, Goecke T, Moeslein G, Kloor M, Gebert J, Kunstmann E, Schulmann K, Ruschoff J, Propping P (2008) Ten recently identified associations between nsSNPs and colorectal cancer could not be replicated in German families. Cancer Lett 271: 153-157

Houlston RS, Webb E, Broderick P, Pittman AM, Di Bernardo MC, Lubbe S, Chandler I, Vijayakrishnan J, Sullivan K, Penegar S, Carvajal-Carmona L, Howarth K, Jaeger E, Spain SL, Walther A, Barclay E, Martin L, Gorman M, Domingo E, Teixeira AS, Kerr D, Cazier JB, Niittymaki I, Tuupanen S, Karhu A, Aaltonen LA, Tomlinson IP, Farrington SM, Tenesa A, Prendergast JG, Barnetson RA, Cetnarskyj R, Porteous ME, Pharoah PD, Koessler T, Hampe J, Buch S, Schafmayer C, Tepel J, Schreiber S, Volzke H, Chang-Claude J, Hoffmeister M, Brenner H, Zanke BW, Montpetit A, Hudson TJ, Gallinger S, Campbell H, Dunlop MG (2008) Meta-analysis of genome-wide association data identifies four new susceptibility loci for colorectal cancer. Nat Genet 40: 1426-1435

Huang Y, Han S, Li Y, Mao Y, Xie Y (2007) Different roles of MTHFR C677T and A1298C polymorphisms in colorectal adenoma and colorectal cancer: a meta-analysis. J Hum Genet 52: 73-85

Hubner R, Houlston R. Polymorphic variation and risk of colorectal cancer. In: Tomlinson IPM (ed). Hereditary Colorectal Cancer

Hubner RA, Houlston RS (2007) MTHFR C677T and colorectal cancer risk: a meta-analysis of 25 populations. Int J Cancer 120: 1027-1035

Jaeger E, Webb E, Howarth K, Carvajal-Carmona L, Rowan A, Broderick P, Walther A, Spain S, Pittman A, Kemp Z, Sullivan K, Heinimann K, Lubbe S, Domingo E, Barclay E, Martin L, Gorman M, Chandler I, Vijayakrishnan J, Wood W, Papaemmanuil E, Penegar S, Qureshi M, Farrington S, Tenesa A, Cazier JB, Kerr D, Gray R, Peto J, Dunlop M, Campbell H, Thomas H, Houlston R, Tomlinson I (2008) Common genetic variants at the CRAC1 (HMPS) locus on chromosome 15q13.3 influence colorectal cancer risk. Nat Genet 40: 26-28

Kemp Z, Carvajal-Carmona L, Spain S, Barclay E, Gorman M, Martin L, Jaeger E, Brooks N, Bishop DT, Thomas H, Tomlinson I, Papaemmanuil E, Webb E, Sellick GS, Wood W, Evans G, Lucassen A, Maher ER, Houlston RS (2006) Evidence for a colorectal cancer susceptibility locus on chromosome 3q21-q24 from a high-density SNP genome-wide linkage scan. Hum Mol Genet 15: 2903-2910

Kerr DJ, Dunn JA, Langman MJ, Smith JL, Midgley RS, Stanley A, Stokes JC, Julier P, Iveson C, Duvvuri R, McConkey CC (2007) Rofecoxib and cardiovascular adverse events in adjuvant treatment of colorectal cancer. N Engl J Med 357: 360 -369 
Krawczak M, Nikolaus S, von Eberstein H, Croucher PJ, El Mokhtari NE Schreiber S (2006) PopGen: population-based recruitment of patients and controls for the analysis of complex genotype-phenotype relationships. Community Genet 9: 55-61

Lichtenstein P, Holm NV, Verkasalo PK, Iliadou A, Kaprio J, Koskenvuo M, Pukkala E, Skytthe A, Hemminki K (2000) Environmental and heritable factors in the causation of cancer - analyses of cohorts of twins from Sweden, Denmark, and Finland. $N$ Engl J Med 343: 78-85

Marchini J, Donnelly P, Cardon LR (2005) Genome-wide strategies for detecting multiple loci that influence complex diseases. Nat Genet 37: $413-417$

Moonesinghe R, Khoury MJ, Liu T, Ioannidis JP (2008) Required sample size and nonreplicability thresholds for heterogeneous genetic associations. Proc Natl Acad Sci USA 105: 617-622

Penegar S, Wood W, Lubbe S, Chandler I, Broderick P, Papaemmanuil E, Sellick G, Gray R, Peto J, Houlston R (2007) National study of colorectal cancer genetics. Br J Cancer 97: $1305-1309$

Porteous M, Dunckley M, Appleton S, Catt S, Dunlop M, Campbell H, Cull A (2003) Is it acceptable to approach colorectal cancer patients at diagnosis to discuss genetic testing? A pilot study. Br J Cancer 89: 1400-1402

Salovaara R, Loukola A, Kristo P, Kaariainen H, Ahtola H, Eskelinen M, Harkonen N, Julkunen R, Kangas E, Ojala S, Tulikoura J, Valkamo E, Jarvinen H, Mecklin JP, Aaltonen LA, de la Chapelle A (2000) Population-based molecular detection of hereditary nonpolyposis colorectal cancer. J Clin Oncol 18: $2193-2200$

Schafmayer C, Buch S, Egberts JH, Franke A, Brosch M, El Sharawy A, Conring M, Koschnick M, Schwiedernoch S, Katalinic A, Kremer B, Folsch UR, Krawczak M, Fandrich F, Schreiber S, Tepel J, Hampe J (2007) Genetic investigation of DNA-repair pathway genes PMS2, MLH1, MSH2, MSH6, MUTYH, OGG1 and MTH1 in sporadic colon cancer. Int J Cancer 121: $555-558$

Tan XL, Nieters A, Kropp S, Hoffmeister M, Brenner H, Chang-Claude J (2008) The association of cyclin D1 G870A and E-cadherin C-160A polymorphisms with the risk of colorectal cancer in a case control study and meta-analysis. Int J Cancer 122: $2573-2580$

Tenesa A, Dunlop MG (2009) New insights into the aetiology of colorectal cancer from genome-wide association studies. Nat Rev Genet (e-pub ahead of print)

Tenesa A, Farrington SM, Prendergast JG, Porteous ME, Walker M, Haq N, Barnetson RA, Theodoratou E, Cetnarskyj R, Cartwright N, Semple C, Clark AJ, Reid FJ, Smith LA, Kavoussanakis K, Koessler T, Pharoah PD, Buch S, Schafmayer C, Tepel J, Schreiber S, Volzke H, Schmidt CO, Hampe J, Chang-Claude J, Hoffmeister M, Brenner H, Wilkening S, Canzian F, Capella G, Moreno V, Deary IJ, Starr JM, Tomlinson IP, Kemp Z, Howarth K, Carvajal-Carmona L, Webb E, Broderick P, Vijayakrishnan J, Houlston RS, Rennert G, Ballinger D, Rozek L, Gruber SB, Matsuda K, Kidokoro T, Nakamura Y, Zanke BW, Greenwood CM, Rangrej J, Kustra R, Montpetit A, Hudson TJ, Gallinger S, Campbell H, Dunlop MG (2008) Genome-wide association scan identifies a colorectal cancer susceptibility locus on $11 \mathrm{q} 23$ and replicates risk loci at $8 \mathrm{q} 24$ and $18 \mathrm{q} 21$. Nat Genet 40: $631-637$

Theodoratou E, Farrington SM, Tenesa A, McNeill G, Cetnarskyj R, Barnetson RA, Porteous ME, Dunlop MG, Campbell H (2008) Modification of the inverse association between dietary vitamin $\mathrm{D}$ intake and colorectal cancer risk by a FokI variant supports a chemoprotective action of Vitamin D intake mediated through VDR binding. Int J Cancer 123: $2170-2179$

Thomas DC, Clayton DG (2004) Betting odds and genetic associations. $J$ Natl Cancer Inst 96: 421-423

Tomlinson I, Webb E, Carvajal-Carmona L, Broderick P, Kemp Z, Spain S, Penegar S, Chandler I, Gorman M, Wood W, Barclay E, Lubbe S, Martin L, Sellick G, Jaeger E, Hubner R, Wild R, Rowan A, Fielding S, Howarth K, Silver A, Atkin W, Muir K, Logan R, Kerr D, Johnstone E, Sieber O, Gray R, Thomas H, Peto J, Cazier JB, Houlston R (2007) A genome-wide association scan of tag SNPs identifies a susceptibility variant for colorectal cancer at 8q24.21. Nat Genet 39: 984-988

Tomlinson IP, Webb E, Carvajal-Carmona L, Broderick P, Howarth K, Pittman AM, Spain S, Lubbe S, Walther A, Sullivan K, Jaeger E, Fielding S, Rowan A, Vijayakrishnan J, Domingo E, Chandler I, Kemp Z, Qureshi M, Farrington SM, Tenesa A, Prendergast JG, Barnetson RA, Penegar S, Barclay E, Wood W, Martin L, Gorman M, Thomas H, Peto J, Bishop DT, Gray R, Maher ER, Lucassen A, Kerr D, Evans DG, Schafmayer C, Buch S, Volzke H, Hampe J, Schreiber S, John U, Koessler T, Pharoah P, van Wezel T, Morreau H, Wijnen JT, Hopper JL, Southey MC, Giles GG, Severi G, Castellvi-Bel S, Ruiz-Ponte C, Carracedo A, Castells A, Forsti A, Hemminki K, Vodicka P, Naccarati A, Lipton L, Ho JW, Cheng KK, Sham PC, Luk J, Agundez JA, Ladero JM, de la Hoya M, Caldes T, Niittymaki I, Tuupanen S, Karhu A, Aaltonen L, Cazier JB, Campbell H, Dunlop MG, Houlston RS (2008) A genome-wide association study identifies colorectal cancer susceptibility loci on chromosomes 10p14 and 8q23.3. Nat Genet 40: 623-630

Tulupova E, Kumar R, Hanova M, Slyskova J, Pardini B, Polakova V, Naccarati A, Vodickova L, Novotny J, Halamkova J, Hemminki K, Vodicka P (2008) Do polymorphisms and haplotypes of mismatch repair genes modulate risk of sporadic colorectal cancer? Mutat Res 648: $40-45$

Volzke H, Werner A, Wallaschofski H, Friedrich N, Robinson DM, Kindler S, Kraft M, John U, Hoffmann W (2005) Occupational exposure to ionizing radiation is associated with autoimmune thyroid disease. J Clin Endocrinol Metab 90: 4587-4592

Wacholder S, Chanock S, Garcia-Closas M, El Ghormli L, Rothman N (2004) Assessing the probability that a positive report is false: an approach for molecular epidemiology studies. J Natl Cancer Inst 96: 434-442

Zanke BW, Greenwood CM, Rangrej J, Kustra R, Tenesa A, Farrington SM, Prendergast J, Olschwang S, Chiang T, Crowdy E, Ferretti V, Laflamme P, Sundararajan S, Roumy S, Olivier JF, Robidoux F, Sladek R, Montpetit A, Campbell P, Bezieau S, O’Shea AM, Zogopoulos G, Cotterchio M, Newcomb P, McLaughlin J, Younghusband B, Green R, Green J, Porteous ME, Campbell H, Blanche H, Sahbatou M, Tubacher E, Bonaiti-Pellie C, Buecher B, Riboli E, Kury S, Chanock SJ, Potter J, Thomas G, Gallinger S, Hudson TJ, Dunlop MG (2007) Genome-wide association scan identifies a colorectal cancer susceptibility locus on chromosome 8q24. Nat Genet 39: $989-994$

Zhang D, Chen C, Fu X, Gu S, Mao Y, Xie Y, Huang Y, Li Y (2008) A metaanalysis of DNA repair gene XPC polymorphisms and cancer risk. J Hum Genet 53: 18-33 